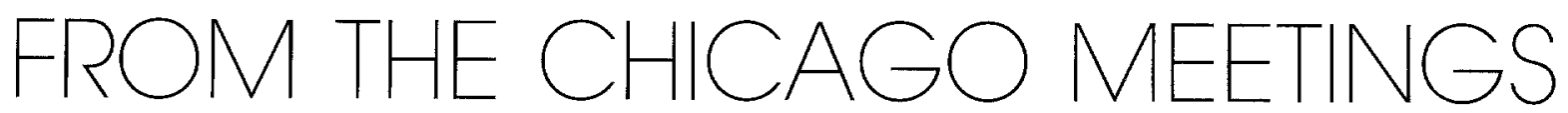

\title{
Pathophysiology of CML: Do defects in integrin function contribute to the premature circulation and massive expansion of the BCR/ABL positive clone?
}

\author{
CATHERINE M. VERFAILLIE, RANDOLPH HURLEY, ROBERT C. H. ZHAO, FELIPE PROSPER, \\ MICHEL DELFORGE, and RAVI BHATIA
}

MINNEAPOLIS, MINNESOTA, LEUVEN, BELGIUM, and DUARTE, CALIFORNIA

\begin{abstract}
Hematopoiesis takes place in close contact with the marrow microenvironment. Normal progenitors adhere through a variety of receptors to stroma and extracellular matrix components, including fibronectin. Adhesion through $\beta$ 1-integrin receptors to fibronectin not only anchor progenitors to the stroma but also result in direct adhesion-mediated signaling that inhibits progenitor proliferation. In contrast to normal hematopoiesis, chronic myelogenous leukemia $(\mathrm{CML})$ is characterized not only by abnormal, premature circulation of primitive progenitors in the blood but also by continuous progenitor proliferation. Although CML progenitors express the same integrin receptors as normal progenitors, they fail to adhere to stroma and fibronectin, suggesting structural or functional abnormalities of these receptors. Furthermore, CML cells present in contact with stroma or fibronectin continue to proliferate, suggesting that failure to adhere through integrin receptors may also underlie the abnormal proliferation of CML progenitors. The observation that integrin-mediated adhesion and proliferation-inhibitory signaling can be restored through treatment with interferon- $\alpha$ or an activating anti- $\beta$ 1-integrin antibody suggests a functional rather than structural defect that may be related to the presence of the $B C R / A B L$ gene rearrangement in these cells. Insights into the role of integrins as adhesion molecules but also receptors that instruct hematopoietic progenitors to survive, proliferate, and possibly differentiate will not only further our understanding of the normal hematopoietic process but also provide insights into diseases characterized by deranged adhesion and proliferation that may lead to novel therapeutic approaches. (J Lab Clin Med 1997;129:584-91)
\end{abstract}

\begin{abstract}
Abbreviations: $\mathrm{CFC}=$ colony-forming cell; $\mathrm{CML}=$ chronic myelogenous leukemia; $F A K=$ focal adhesion kinase; $\lg G=$ immunoglobulin $G$; $L T C-I C=$ long-term culture-initiating cell; MAPK = mitogen-activated protein kinase; PI3-K = phosphatidyl inositol-3 kinase; STAT = signal transducer and activator of transcription
\end{abstract}

From the Stem Cell Biology Program and Division of Hematology, Department of Medicine, University of Minnesota, Minneapolis; the Department of Medicine, University of Leuven; and the Department of Medicine, City of Hope National Medical Center, Duarte.

Supported in part by National Institutes of Health Grants RO1HL-49930 and PO1-CA-65493 and by the University of Minnesota Bone Marrow Transplant Research Fund, The Leukemia Task Force, and the University of Minnesota Hospitals and Clinics. C.M.V. is a Scholar of the Leukemia Society of America.
Presented in part at the Sixty-ninth Annual Meeting of the Central Society for Clinical Research, Sept. 19 through 21, 1996, Chicago, Ill. Dr. Verfaillie is the recipient of a 1996 CSCR Outstanding Investigator Award.

Submitted for publication Jan. 6, 1997; accepted Jan. 8, 1997.

Reprint requests: Catherine M. Verfaillie, MD, Department of Medicine, Box 480, 520 Delaware St. SE, Minneapolis, MN 55455. Copyright (C) 1997 by Mosby-Year Book, Inc.

$0022-2143 / 97 \$ 5.00+0 \quad \mathbf{5 / 1 / 8 1 2 8 8}$ 


\title{
Contact with stromal fibronectin inhibits normal CFC proliferation
}

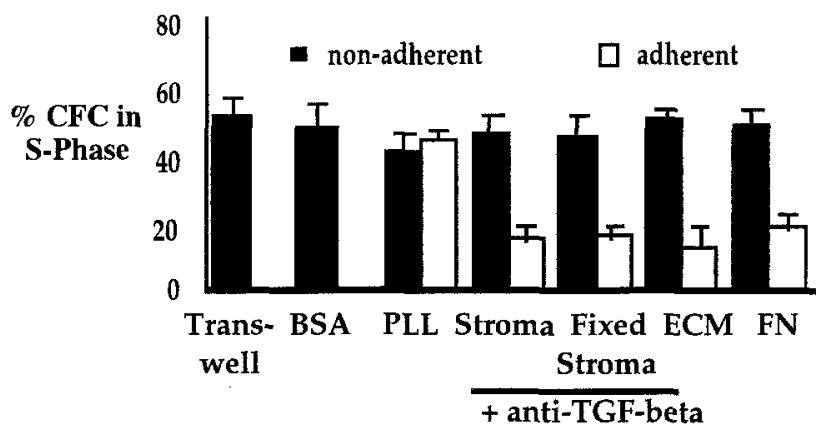

\section{Antibody mediated engagement of $\beta 1$-integrins inhibits normal CFC proliferation}

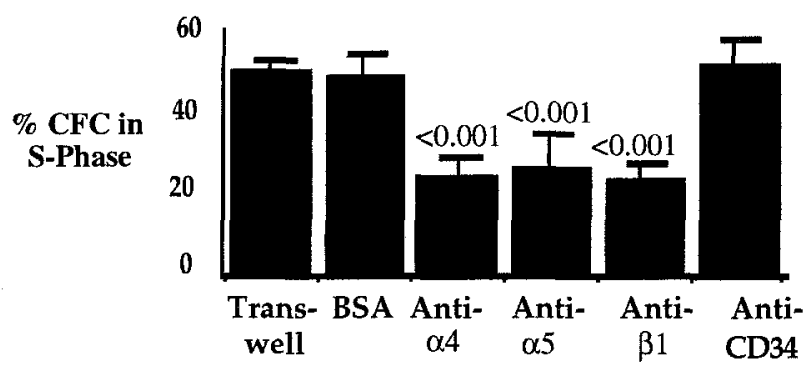

\begin{abstract}
Fig. 1. Integrin-mediated proliferation inhibition of normal hematopoietic progenitors. Normal steadystate marrow-derived CD34+ cells were induced to proliferate by incubation in stroma-conditioned medium for 3 to 4 days. Cells were then cocultured with either bovine serum albumin, poly-L-lysine, stromal feeders, or glutaraldehyde-fixed stromal feeders in the presence or absence of anti-transforming growth factor- $\beta$-neutralizing antibodies or with the C-terminal $\alpha 4 \beta 1$-integrin-binding fragment ( $33 / 66 \mathrm{kd})$ of fibronectin for 4 to 6 hours. Alternatively, cells were incubated with blocking anti- $\alpha 4$, anti- $\alpha 5$, anti- $\beta 1$-integrin antibodies or control mouse $\operatorname{IgG}$ for 30 minutes, followed by incubation with a goat anti-mouse IgG for 4 to 6 hours. Afterwards, cells were subjected to cold or tritiated thymidine before plating in methylcellulose progenitor assay to determine the fraction of cells in S phase. ${ }^{15,16}$
\end{abstract}

Hematopoiesis is a complex process in which hematopoietic stem cells proliferate and differentiate into myeloid and lymphoid lineage committed progenitors. These committed progenitors undergo further multiplications before they terminally differentiate into mature blood elements. The process of myelopoiesis, B-lymphopoiesis, T-lymphopoiesis, and natural killer cell generation occurs in close proximity with a permissive microenvironment, which in adult life is provided in the bone marrow. The factors responsible and necessary for an orderly hematopoietic process are not yet understood. The bone marrow microenvironment contains "stromal" cells, such as macrophages, endothelial cells, fibroblasts and osteoblasts. These cells are responsible for the production and deposition of a complex extracellular matrix and local production and concentration of hematopoietic cytokines. Hematopoietic cells inter- act through specific cell surface expressed receptors with either immobilized or secreted growth promoting/inhibitory cytokines and with adhesive ligands present on stromal cells or extracellular matrix components. ${ }^{1}$ It is believed that the concerted action of all these interactions results in ordered, normal hematopoiesis.

\section{INTEGRINS AND NORMAL HEMATOPOIESIS}

That $\beta 1$-integrins may play an important role in localizing progenitors in the marrow microenvironment follows from a number of in vivo and in vitro observations. First, engraftment of murine stem cells can be inhibited by anti- $\alpha 4 \beta 1$ antibodies. ${ }^{2,3}$ Likewise, homing of human stem cells to a xenogeneic ovine marrow microenvironment can be inhibited by anti-human $\alpha 4$ antibodies. ${ }^{4}$ Intravenous administration of anti- $\alpha 4$ antibodies, but not 


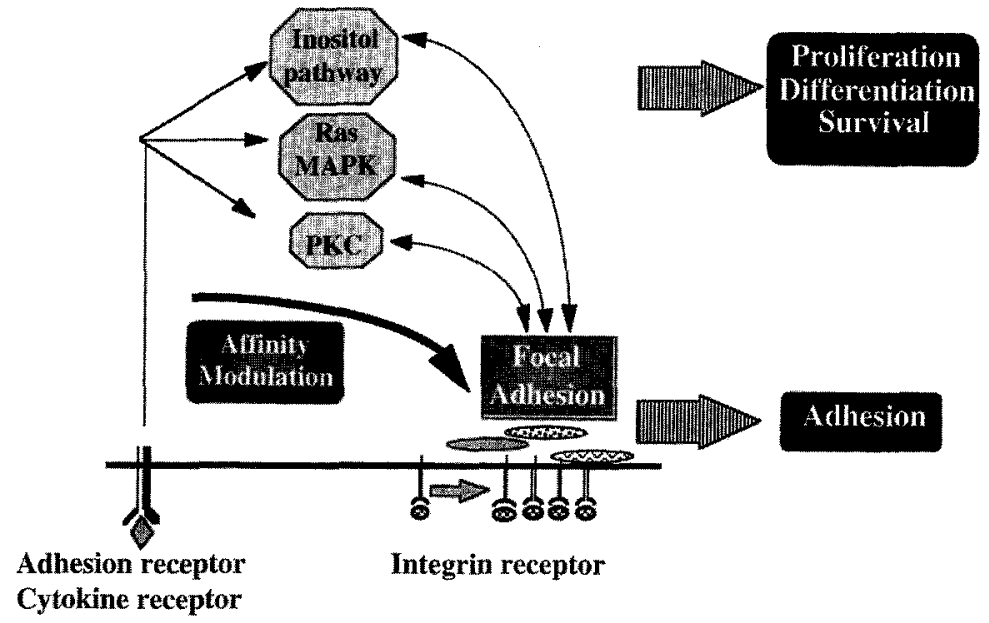

Fig. 2. Focal adhesions. Integrins, cell surface glycoproteins responsible for both cell-ECM adhesion and cell-cell adhesion events, consist of an $\alpha$-subunit and $\beta$-subunit. The extracellular domain is responsible for ligand recognition and binding. The intracellular domain of the $\beta 1$-subunit colocalizes with cytoskeletal proteins in focal contacts. Engagement of integrins by their ligand results in the recruitment of FAK, c-Src, and other adaptor and signaling molecules that in turn activate a number of signal transduction cascades, such as the RAS/MAPK and the inositol and protein kinase C pathways, through which they can affect cell proliferation, differentiation, and survival (outside-in signaling). In addition, the interaction of the $\beta 1$-integrin intracellular domain with the cell cytoskeleton allows transfer of signals originating from cytokine stimulation or other adhesion receptors to the integrin to modify its affinity status (inside-out signaling).

anti- $\beta 2$-integrin antibodies, to baboons results in peripheralization of granulocyte/macrophage colonyforming cells and stem cells. ${ }^{5}$ Finally, $\beta 1$-defective hematopoietic stem cells can not successfully compete with wild-type stem cells in competitive engraftment experiments because of their inability to migrate. ${ }^{6}$ All these studies indicate that $\alpha 4 \beta 1$-dependent interactions are important to localize progenitors in the marrow microenvironment and to allow their migration and adhesion to the microenvironment.

In vitro, it can be demonstrated that undifferentiated and lineage-committed progenitors from normal marrow adhere in a lineage-specific and differentiation stage-specific manner to several extracellular matrix components, including heparansulfate, ${ }^{7}$ thrombospondin, ${ }^{8}$ and fibronectin. ${ }^{9} \mathrm{We}$ and others have demonstrated that primitive progenitors, functionally defined as LTC-ICs, and more committed CFCs adhere to the vascular cell adhesion molecule and fibronectin present in stroma ${ }^{9-12}$ through the $\alpha 4 \beta 1$ and $\alpha 5 \beta 1$ integrins and the cell surface proteoglycan CD44. In addition, progenitors express $\beta 2$-integrins whose role in progenitor-marrow microenvironment interaction is less clear ${ }^{12}$ and selectins that may allow them to interact with endothelial cells. ${ }^{13}$

As has been described for other biologic systems, integrin-mediated interactions between progenitors and fibronectin or other stromal components may also directly affect progenitor proliferation or differentiation (or both). In a series of experiments we have demonstrated that contact with stromal extracellular matrix, more specifically fibronectin, inhibits proliferation of CFCs and LTC-ICs. This is mediated in part through engagement of integrins, suggesting that integrin stimulation can directly affect progenitor proliferation. For instance, 2 to 3 times more CFCs are generated and 2 to 3 times more LTC-ICs are maintained when $\mathrm{CD}_{3} 4^{+}$cells are cultured for 5 to 8 weeks in stromal cultures but separated from stroma (noncontact culture) than when cultured in direct contact with the stromal cells (contact culture). ${ }^{14}$ Because the continued addition of peptides representing cell adhesion sites in the $\mathrm{C}$-terminal domain of fibronectin to stromacontact cultures increases the number of CFCs recovered after 5 weeks, ${ }^{15}$ similar to what we see in noncontact cultures, we hypothesized that direct contact between progenitors and stromal elements may inhibit proliferation of progenitors, leading to decreased production of CFCs and maintenance of LTC-ICs. We therefore examined the effect of coculture of CFCs with stromal ligands on their proliferation (Fig. 1). ${ }^{15}$ Coculture of proliferating CFCs with glutaraldehyde-fixed stroma inhibits CFC pro- 

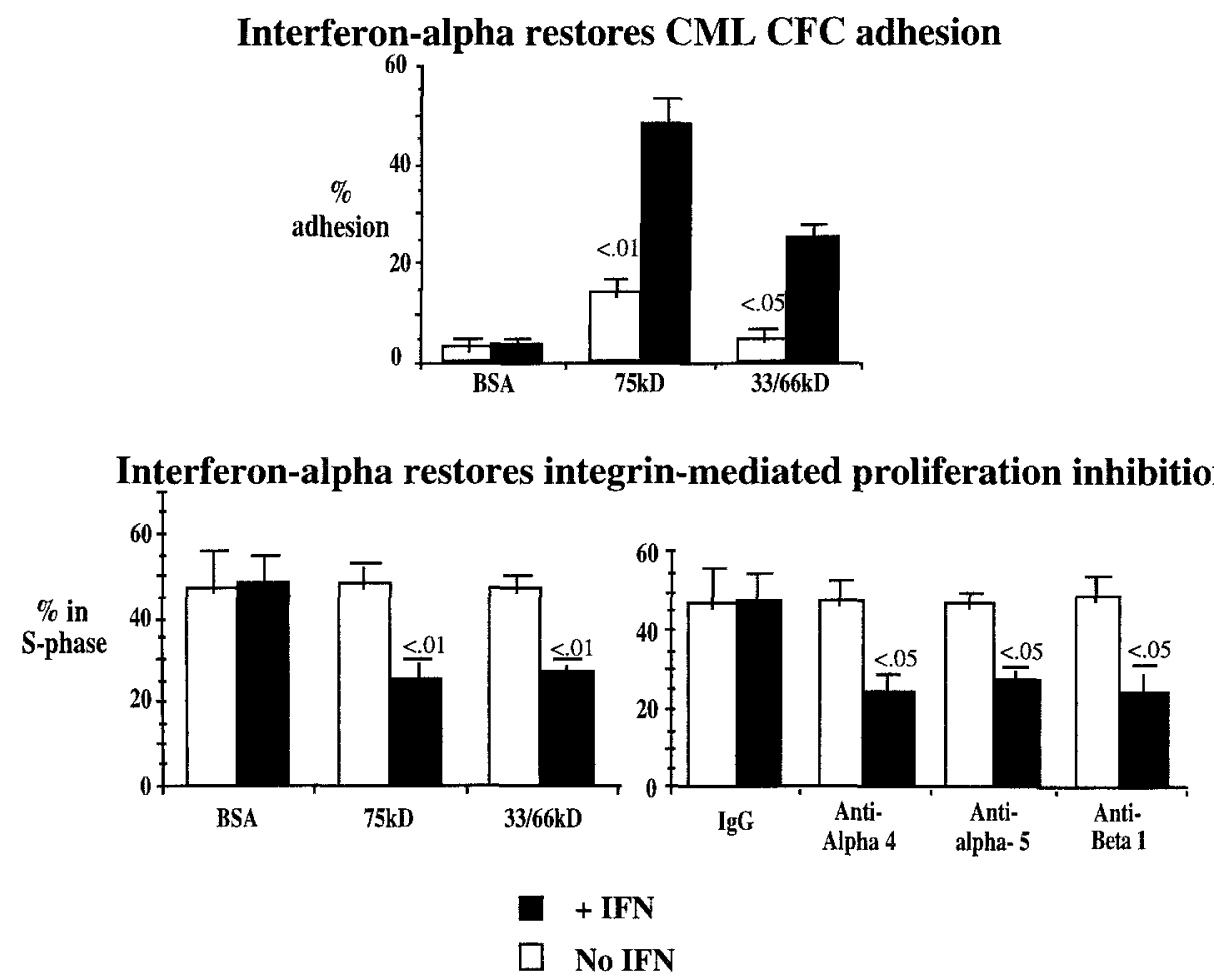

Fig. 3. Interferon- $\alpha$ restores integrin-dependent adhesion and integrin-mediated proliferation inhibition of CML hematopoietic progenitors. CML steady-state marrow-derived CD34+/HLA-DR+ cells were induced to proliferate by incubation in stroma-conditioned medium for 3 to 4 days. During the last 48 hours, $1000 \mathrm{U}$ interferon- $\alpha$ was added to some of the samples. Cells were then cocultured with either bovine serum albumin or with the GRGDS containing $\alpha 5 \beta 1$-integrin binding fragment $(75 \mathrm{kd})$ or the C-terminal $\alpha 4 \beta 1$-integrin binding fragment ( $33 / 66 \mathrm{kd}$ ) of fibronectin for 2 to 6 hours. Alternatively, cells were incubated with blocking anti- $\alpha 4$-, anti- $\alpha 5$-, or anti- $\beta 1$-integrin antibodies or control mouse IgG for 30 minutes, followed by incubation with a goat anti-mouse IgG for 4 to 6 hours. Afterwards, adherent and nonadherent cells were either replated directly in a methylcellulose assay to determine the fraction of committed progenitors that adhere to fibronectin or were subjected to cold or tritiated thymidine before plating in methylcellulose progenitor assay to determine the fraction of cells in $\mathrm{S}$ phase.

liferation that can be prevented by antibodies against $\alpha 4$. Coculture of CFCs with $\alpha 5$-binding or with $\alpha 4$-binding domains of fibronectin inhibits CFC proliferation. ${ }^{16}$ Finally, incubation of $\mathrm{CD} 34+$ cells with blocking anti- $\alpha 4, \alpha-5$, or $-\beta 1$ antibodies and a secondary goat anti-mouse antibody induces receptor capping and cytoskeletal rearrangement, which leads to inhibition of CFC proliferation. ${ }^{16}$ These studies demonstrate thus that aside from anchoring progenitors in the microenvironment, $\beta 1$-integrins may also be responsible for transferring growth modulatory signals.

Integrins are a family of divalent cation-dependent cell surface glycoproteins responsible for both cell-extracellular matrix adhesion and cell-cell adhesion events. ${ }^{17}$ Integrins are heterodimeric as a result of the noncovalent association between an $\alpha$-subunit and $\beta$-subunit. Integrins have a large, heterodimeric extracellular domain responsible for ligand recognition and binding. Ligand specificity is dictated mostly by the $\alpha$-chain. Integrins have a small membrane spanning domain and an intracellular domain. The intracellular domain of the $\beta 1$-subunit may have a dual role in that it mediates the initial steps in a signal transduction cascade as a result of binding of the integrin to its ligand (outside-in) and is responsible for affinity modulation of the integrin in response to signals provided to the cells through cytokines or other adhesion receptors (inside-out) ${ }^{17}$ (Fig. 2). Integrins colocalize with $\alpha$-actinin, talin, vinculin, and F-actin in focal contacts. ${ }^{17-19}$ Members of the Rho family, including Rho and Rac, influence the formation and dynamic stability of actin-based cytoskeletal structures. Talin and the $\beta 1$-integrin itself bind to the FAK ${ }^{20}$ Thus engagement of integrins results in the recruitment of FAK to focal contacts and its autophosphorylation. Subsequent recruitment and activation of c-Src, paxillin, Crk, Grb-2, and the p85 subunit PI3K. ${ }^{18-20}$ This can result in the activation of the Ras/MAPK pathway, ${ }^{21}$ 


\title{
The $\beta 1$ activating antibody, $8 \mathrm{~A} 2$, restores adhesion and adhesion-mediated signaling in CML
}
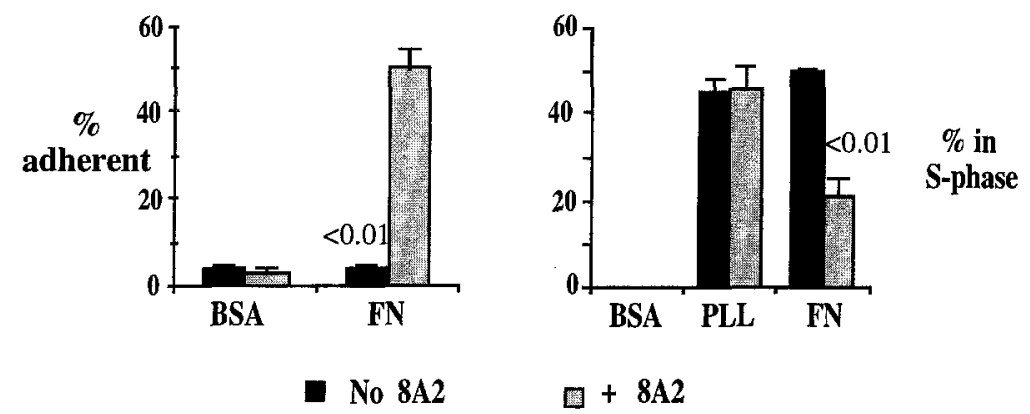

\begin{abstract}
Fig. 4. The activating anti- $\beta 1$-integrin antibody, $8 \mathrm{~A} 2$, restores integrin-dependent adhesion and integrinmediated proliferation inhibition of CML hematopoietic progenitors. CML steady-state marrow-derived CD34+/HLA-DR + cells were induced to proliferate by incubation in stroma-conditioned medium for 3 to 4 days. Before adhesion or adhesion-mediated proliferation inhibition assays, cells were incubated with the activating antibody 8A2 (a gift from Dr. Nick Kovach, University of Washington, Seattle) or control mouse IgG. Cells were then cocultured with either bovine serum albumin or fibronectin for 2 to 6 hours. Adherent and nonadherent cells were either replated directly in methylcellulose assay to determine the fraction of committed progenitors that adhere to fibronectin or were subjected to cold or tritiated thymidine before plating in methylcellulose progenitor assay to determine the fraction of cells in $S$ phase.
\end{abstract}

changes in the expression of immediate-early inflammatory response genes, ${ }^{22}$ and alterations in the levels of cyclins ${ }^{23}$ and cyclin-associated molecules, ${ }^{24}$ all of which can affect cell proliferation, differentiation, and survival.

How these observations relate to the assembly of focal contacts that allow adhesion or integrin-dependent signaling that affects proliferation or differentiation (or both) of hematopoietic cells is still unknown. We have preliminary evidence that integrin-mediated alterations in progenitor proliferation depends on reorganization of the cytoskeleton ${ }^{16}$ and that integrin engagement on $\mathrm{CD} 34^{+}$cells results in the phosphorylation of FAK (unpublished observations). However, the nature of other downstream intracellular structural and signal molecules involved in focal contact formation leading to adhesion, migration, and growth inhibition observed in the hematopoietic system after engagement of integrins is still unknown.

\section{DEFECTS IN INTEGRINS IN CML HEMATOPOIESIS}

CML is a malignant disease of the pluripotent hematopoietic stem cell characterized by the Philadelphia chromosome $(\mathrm{Ph})^{25}$ and a rearrangement between the BCR gene (break-point cluster region) and the $\mathrm{ABL}$ gene. ${ }^{26}$ Clinically, CML is characterized by a massive expansion of immature progenitors and precursors that leave the marrow microenvironment prematurely. ${ }^{27}$ Although normal progenitors coexist with the malignant clone in CML, their growth seems to be inhibited, possibly as a result of abnormalities inherent to the CML marrow microenvironment. ${ }^{28}$

Why CML progenitors circulate prematurely in the blood is not completely understood. We and others have demonstrated that, compared with normal progenitors, $\mathrm{Ph}^{+}$CML LTC-ICs and CFCs adhere significantly less to stroma ${ }^{29,30}$ or fibronectin ${ }^{31}$ even though $\mathrm{Ph}^{+}$progenitors express normal numbers of $\alpha 4, \alpha 5$, and $\beta 1^{29,31}$ adhesion receptors. This may explain, at least in part, their premature circulation. The mechanisms that underlie the massive expansion of $\mathrm{Ph}^{+}$hematopoietic progenitors, precursors, and mature cells are also not understood. Chronic phase CML progenitors are not growth factor-independent nor are they hypersensitive to cytokines. ${ }^{32}$ There is evidence that CML progenitors are less subject to apoptosis when cultured under unfavorable conditions ex vivo, ${ }^{33,34}$ which may lead to accumulation of the malignant clone. In comparison with normal progenitors, more CML progenitors are proliferating, even though the cell cycle duration of CML progenitors my be longer than that of normal progenitors. ${ }^{35}$ Because adhesion to the microenvironment in the normal hematopoietic process may be important not only in localizing progenitors in the marrow but also in regulating their proliferation, we examined whether defective integrin-mediated adhesion to stromal elements in CML may explain the abnormal circulation and also proliferation observed in this disease.

A number of studies have demonstrated that $\mathrm{Ph}^{+}$ CFCs and LTC-ICs are not subject to normal 


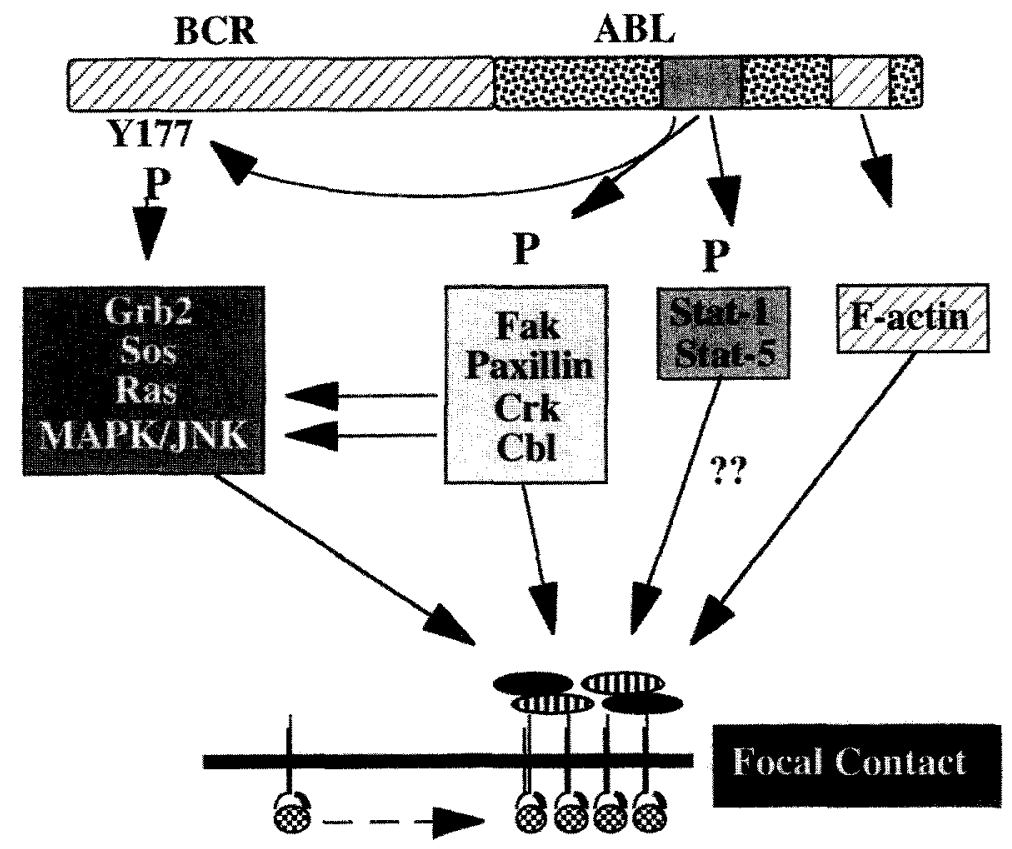

Fig. 5. Possible interactions between $\mathrm{p} 210^{\mathrm{BCR} / \mathrm{ABL}}$ and integrin-dependent signals. The BCR/ABL mRNA encoes for the $\mathrm{P} 210^{\mathrm{BCR} / \mathrm{ABL}}$ tyrosine kinase. $\mathrm{P} 210^{\mathrm{BCR} / \mathrm{ABL}}$ has increased tyrosine kinase activity, resulting in autophosphorylation of $\mathbf{P} 210^{\mathrm{BCR} / \mathrm{ABL}}$ itself, FAK, Crkl, Cbl, and possibly STAT 1 and STAT 5. Phosphoryla-

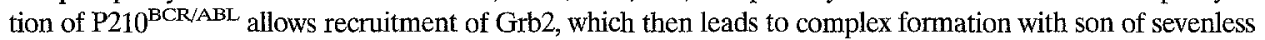
(Sos) and activation of Ras. Finally, compared with p145 ${ }^{\mathrm{ABL}}, \mathrm{P} 210^{\mathrm{BCR} / \mathrm{ABL}}$ binds significantly more to F-actin.

growth inhibitory signals when they are present in contact with stroma. ${ }^{36,37}$ Likewise, contact with the $\alpha 4 \beta 1$ and $\alpha 5 \beta 1$ binding domains of fibronectin or direct engagement of integrins with anti-integrin antibodies ${ }^{37}$ does not inhibit $\mathrm{Ph}^{+} \mathrm{CFC}$ proliferation. In contrast to normal progenitors, incubation of CML progenitors or cell lines that contain the BCR/ ABL cDNA with blocking anti- $\beta 1$ antibodies does not result in receptor capping. ${ }^{38}$ Interestingly, integrin-dependent adhesion and proliferation inhibitory signaling can be restored by preincubating CML cells with either interferon- $\alpha^{29,37}$ (Fig. 3) antisense oligonucleotides against $\mathrm{BCR} / \mathrm{ABL}^{39}$ or with tyrosine kinase inhibitors specific for the $\mathrm{BCR} / \mathrm{ABL}$ oncoprotein. ${ }^{40}$ This indicates that integrins on CML progenitors are functionally rather than structurally abnormal. Integrin-dependent adhesion requires that the integrin binds to its ligand, which depends on the affinity state of the integrin and on postreceptor events that allow assembly of focal adhesions needed for firm adhesions and transfer of outside-in signals (to affect proliferation). This led us to hypothesize that the defect in CML may be that integrins are present in a low-affinity state or that the interaction of integrins with cytoskeletal elements is abnormal, resulting in failure to laterally associate, adhere, and transfer microenvironmental growthinhibitory signals. Although affinity studies have not yet been performed on primary CML progenitors, we have shown that treatment with the activating anti- $\beta 1$ antibody, $8 \mathrm{~A} 2,{ }^{41}$ restores adhesion and subsequent adhesion-mediated proliferation inhibition of CML progenitors when in contact with fibronec$\operatorname{tin}^{42}$ (Fig. 4). This provides at least indirect evidence that $\beta 1$-integrins may be present in a low-affinity state on CML progenitors. It is well known that inside-out signals transferred from other cell surface adhesion receptors or cytokine receptors via the cytoskeleton to integrins can switch integrins to a functional high-affinity state. Our observation that receptor capping is defective ${ }^{38}$ supports the hypothesis that decreased receptor affinity may be related to abnormal interactions between the integrins and cytoskeletal components, which do not allow inside-out activation of the integrin. Thus, abnormal interactions between integrins and one or more components of focal adhesions could then explain not only the poor integrin-mediated adhesion and defective growthinhibitory outside-in signal transduction but also the low-affinity state of integrins on CML progenitors.

These studies suggest strongly that the BCR/ABL gene rearrangement may be responsible for the lowaffinity state of $\beta 1$-integrins on the majority of CML progenitors or the defective interactions between integrins and other components of focal adhesions in CML. However, it remains to be determined how 
BCR/ABL causes these defects. The BCR/ABL mRNA encodes for the $\mathrm{P} 210^{\mathrm{BCR} / \mathrm{ABL}}$ tyrosine kinase that is necessary and sufficient for malignant transformation $^{43,44}$ (Fig. 5). p210 ${ }^{\mathrm{BCR} / \mathrm{ABL}}$ has, in comparison with $\mathrm{p} 145^{\mathrm{ABL}}$, increased tyrosine kinase activity, resulting in autophosphorylation of the oncoprotein. ${ }^{45}$ This allows recruitment of the adaptor protein, Grb2, and activation of Ras. Activation of Ras may also be due to $\mathrm{p} 210^{\mathrm{BCR} / \mathrm{ABL}}$-dependent phosphorylation of additional adaptor proteins such as $\mathrm{Crkl}^{46}$ and $\mathrm{Cbl} .{ }^{47}$ Because activation of Ras/MAPK can alter the type of focal contact assembled after engagement of integrins, ${ }^{48}$ it is possible that activation of Ras by $\mathrm{p} 210^{\mathrm{BCR} / \mathrm{ABL}}$ may affect both integrinmediated adhesion and signaling in CML. Aside from activating the Ras pathway, $\mathrm{p} 210^{\mathrm{BCR} / \mathrm{ABL}}$ phosphorylates and activates a number of other intracellular proteins including $\mathrm{FAK}^{49}{ }^{49}$ paxillin, ${ }^{50} \mathrm{Crkl}^{46}$ and PI3-K, ${ }^{51}$ all of which are required for focal contact formation and for transfer of signal events related to integrin stimulation. For instance, because integrin-mediated signaling requires recruitment and activation of FAK and paxillin, ${ }^{17-20}$ one might speculate that chronic phosphorylation of either of these molecules may result in their inability to participate in the integrin-mediated signaling cascade. Finally, increased binding of $\mathrm{p} 210^{\mathrm{BCR} / \mathrm{ABL}}$ to $\mathrm{F}$-actin ${ }^{52}$ and therefore indirectly to integrins may lead to the inability of integrins to laterally associate and form caps and to localize to focal adhesions where they both transfer outside-in and accept inside-out signals.

\section{CONCLUSION}

Additional studies will be needed to identify structural and signal molecules associated with $\beta 1$ integrins in membrane-associated focal contact complexes that are required to induce firm adhesion and to induce migration or transfer growth regulatory signals in normal hematopoietic progenitors. Such studies will provide significant new insights into mechanisms involved not only in survival, proliferation, and differentiation of normal progenitors but also in mobilization and engraftment of normal hematopoietic progenitors. Such studies will also lead to a better understanding of abnormal hematopoietic processes characterized by increased or decreased circulation and expansion of progenitors, which may ultimately provide us with novel therapies for such disorders.

\section{REFERENCES}

1. Verfaillie CM, Hurley R, Bhatia R, McCarthy JB. Role of bone marrow matrix in normal and abnormal hematopoiesis. Crit Rev Oncol/Hematol 1994;16:201-4.
2. Williams DA, Rios M, Stephens C, Patel VP. Fibronectin and VLA-4 in haematopoietic stem cell-microenvironment interactions. Nature 1991;352:438-41.

3. Papayannopoulou T, Craddock C, Nakamoto B, Priestley GV, Wolf SN. The VLA4/VCAM adhesion pathway defines contrasting mechanisms of lodging of transplanted murine hematopoietic progenitors between bone marrow and spleen. Proc Natl Acad Sci USA 1995;92:9647-51.

4. Zanjani E, Papayanopoulou T. Human CD34+ cells transplanted in utero in sheep fetuses treated with anti-human VLA $^{4}$ remain "homeless" and persist in circulation [abstract]. Blood 1994;84(suppl 1)1962.

5. Papayannopoulou T, Nakamato B. Systemic treatment of primates with anti-VLA4 leads to an immediate egress of hemopoietic progenitors to periphery. Proc Natl Acad Sci USA 1993;90:9374-8.

6. Hirsch E, Iglesias A, Potocnik AJ, Hartmann U, Fässler R. Impaired migration but not differentiation of haematopoietic stem cells in the absence of $\beta 1$ integrins. Nature 1996;380:171-5.

7. Bruno E, Luikart SD, Long MW, Hoffman R. Marrowderived heparan sulfate proteoglycan mediates the adhesion of hematopoietic progenitor cells to cytokines. Exp Hematol 1995;23:1212-7.

8. Long MW, Dixit VM. Thrombospondin functions as a cytoadhesion molecule for human hematopoietic progenitor cells. Blood 1990;75:2311-8.

9. Verfaillie CM, McCarthy JB, McGlave PB. Differentiation of primitive human multipotent hematopoietic progenitors into single lineage clonogenic progenitors is accompanied by alterations in their interaction with fibronectin. $\mathbf{J}$ Exp Med 1991;174:693-703.

10. Simmons PJ, Masinovsky B, Longenecker BM, Berenson R, Torok-Storb B, Gallatin WM. Vascular cell adhesion molecule-1 expressed by bone marrow stromal cells mediates the binding of hematopoietic progenitor cells. Blood 1992;80: 388-95.

11. Verfaillie CM, Benis A, Iida G, McGlave PB, McCarthy J. Adhesion of committed human hematopoietic progenitors to synthetic peptides in the C-terminal heparin-binding domain of fibronectin: cooperation between the integrin $\alpha 4 \beta 1$ and the CD44 adhesion receptor. Blood 1994;84: 1802-12.

12. Teixidó J, Hemler ME, Greenberger JS, Anklesaria P. Role of $\beta 1$ and $\beta 2$ integrins in the adhesion of human CD34 ${ }^{\text {hi }}$ stem cells to bone marrow stroma. J Clin Invest 1992;90:358-67.

13. Dercksen MW, Gerritsen WR, Rodenhuis S, et al. Expression of adhesion molecules on CD34+ cells: CD34+ Lselectin + cells predict a rapid platelet recovery after peripheral blood stem cell transplantation. Blood 1995;85: 3313-22.

14. Verfaillie CM. Direct contact between progenitors and stroma is not required for human in vitro hematopoiesis. Blood 1992;79:2821-6.

15. Hurley RW, McCarthy JB, Verfaillie CM. Direct adhesion to bone marrow stroma via fibronectin receptors inhibits hematopoietic progenitor proliferation. J Clin Invest 1995; 96:511-9.

16. Hurley R, McCarthy JB, Verfaillie CM. Clustering of integrins results in proliferation inhibition of committed hematopoietic progenitors through mechanisms involving the cell cytoskeleton. Exp Hematol (in press).

17. Schwartz MA, Schaller MD, Ginsberg MH. Biology of Integrins: emerging paradigms of signal transduction. Annu Rev Cell Dev 1995;11:549-99. 
18. Zigmond SH. Signal transduction and actin filament organization. Curr Opin Cell Biol 1996;8:66-73.

19. Craig SW, Johnson RP. Assembly of focal adhesions: progress, paradigms, and portents. Curr Opin Cell Biol 1996; $8: 74-85$.

20. Schaller MD, Parsons JT. Focal adhesion kinase and associated proteins. Curr Opin Cell Biol 1994;6:705-10.

21. Schlaepfer DD, Hanks SK, Hunter T, van der Geer P. Integrin-mediated signal transduction linked to Ras pathway by GRB2 binding to focal adhesion kinase. Nature 1994;372: 786-9.

22. Yurochko AD, Liu DY, Eierman D, Haskill S. Integrins as a primary signal transduction molecule regulating monocyte immediate-early gene induction. Proc Natl Acad Sci USA 1992;89:9034-8.

23. Zhu X, Ohtsubo M, Böhmer RM, Roberts JM, Assosian RK. Adhesion-dependent cell cycle progression linked to the expression of cyclin D1, activation of cyclin E-cdk2, and phosphorylation of the retinoblastoma protein. J Cell Biol 1996; 133:391-403.

24. Guadagno TM, Ohtsubo M, Roberts JM, Assosian RK. A link between cyclin A expression and adhesion-dependent cell cycle progression. Science 1993;262:1572-5.

25. Fialkow PJ, Jacobson RJ, Papayannopoulou TH. Chronic myelocytic leukemia: clonal origin in a stem cell common to the granulocyte, erythrocyte, platelet and monocyte/macrophage. Am J Med 1977;63:125-31.

26. Rowley JD. The Philadelphia chromosome translocation: a paradigm for understanding leukemia. Cancer 1990;65:217882.

27. Bartram CR, deKlein A, Hagemeijer A, et al. Translocation of the $c$-abl oncogene adjacent to a translocation break point in chronic myelocytic leukemia. Nature 1983; 306:277-80.

28. Bathia R, Dewald G, McGlave P, Verfaillie CM. Abnormalities of the bone marrow microenvironment in chronic myelogenous leukemia are related to maliganant macrophages. Blood 1995;85:3636-45.

29. Bhatia R, Wayner E, McGlave P, Verfaillie CM. Interferon- $\alpha$ restores adhesion of malignant progenitors in CML by restoring $\beta 1$ integrin function. J Clin Invest 1994;94:384-91.

30. Gordon MY, Dowdling CR, Riley GP, Goldman JM, Greaves MF. Altered adhesive interactions with marrow stroma of hematopoietic progenitor cells in chronic myeloid leukaemia. Nature 1984;328:342-4.

31. Verfaillie CM, JB McCarthy, PB McGlave. Mechanisms underlying abnormal trafficking of malignant progenitors in chronic myelogenous leukemia. Decreased adhesion to stroma and fibronectin but increased adhesion to the basement membrane components laminin and collagen type IV. J Clin Invest 1992;90:1232-41.

32. Bedi A, Griffin CA, Barber JP, Vala MS, Hawkins AL, Sharkis SJ, et al. Growth factor mediated terminal differentiation of chronic myeloid leukemia. Cancer Res 1994;54: 5535-8.

33. Bedi A, Zehnbauer BA, Barber JP, Sharkis SJ, Jones RJ. Inhibition of apoptosis by BCR-ABL in chronic myeloid leukemia. Blood 1994;83:2048-58.

34. McGahon A, Bissonnette R, Schmitt M, Cotter KM, Green DR, Cotter TG. BCR-ABL maintains resistance of chronic myelogenous leukemia cells to apoptotic cell death. Blood 1994;83:1179-86.

35. Strife A, Clarkson B. Biology of chronic myelogenous leukemia: is discordant maturation the primary defect? Semin Hematol 1988;25:1-19.
36. Eaves AC, Cashman JD, Gaboury LA, Kalousek DK, Eaves CJ. Unregulated proliferation of primitive chronic myeloid leukemia progenitors in the presence of normal marrow adherent cells. Proc Natl Acad Sci USA 1986;83:5306-10.

37. Bhatia R, McCarthy JB, Verfaillie CM. Interferon- $\alpha$ restores normal $\beta 1$-integrin mediated negative regulation of chronic myelogenous leukemia progenitor proliferation. Blood 1996; 87:3883-91.

38. Bhatia R, Munthe H, Verfaillie CM. Decreased $\beta 1$-integrin receptor capping in $\mathrm{CML}$ progenitors reflecting abnormal receptor-cytoskeletal interactions is normalized by inteferon- $\alpha$ [abstract]. Blood 1996;88(suppl 1):2537.

39. Bhatia $\mathrm{R}$, Verfaillie $\mathrm{CM}$. Inhibition of $\mathrm{BCR} / \mathrm{ABL}$ expression by anti-sense oligonucleotides normalizes $\beta 1$-integrin mediated adhesion and regulation of proliferation in chronic myelogenous leukemia [abstract]. Blood 1995;86(suppl 1)1740.

40. Bhatia R, Verfaillie CM. Inhibition of BCR/ABL tyrosine kinase activity by tyrphostin AG957 restores $\beta 1$-integrin mediated microenvironmental regulation of hematopoietic progenitor proliferation [abstract]. Blood 1996;88(supp] 1):2668.

41. Kovach NL, Carlos TM, Yee E, Harlan JM. A monoclonal antibody to $\beta 1$ integrin [CD29] stimulates VLA-dependent adherence of leukocytes to human umbilical vein endothelial cells and matrix components. J Cell Biol 1992;116:499-509.

42. Lundell BI, McCarthy JB, Kovach NL, Verfaillie CM. Adhesion to fibronectin (FN) induced by the activating anti-integrin- $\beta 1$ antibody, $8 \mathrm{a} 2$, restores adhesion mediated inhibition of CML progenitor proliferation. Blood 1996; 87:2450-8.

43. Daley GQ, Van Etten RA, Baltimore D. Induction of chronic myelogenous leukemia in mice by the $\mathrm{P} 210^{\mathrm{bcr} / \mathrm{abl}}$ gene of the Philadelphia chromosome. Science 1990;247:824-9.

44. Gishizky ML, Witte ON. Initiation of dysregulated growth of multipotent progenitor cells by bcr-abl in vitro. Science 1992; 256:836-9.

45. Pendergast AM, LA Quilliam, LD Cripe, et al. BCR-ABLInduced oncogenesis is mediated by direct interaction with the SH2 domain of the GRB-2 adaptor protein. Cell 1993; 75:175-85.

46. Oda T, Heaney C, Hagopian JR, Okuda K, Griffin JD, Druker BJ. Crkl is the major tyrosine-phosphorylated protein in neutrophils from patients with chronic myelogenous leukemia. J Biol Chem 1994;269:22925-8.

47. Sattler $\mathbf{M}$, Salgia $R$, Okuda $\mathbf{K}$, et al. The proto-oncogene product $\mathrm{p} 120^{\mathrm{CBL}}$ and the adaptor protein CRKL and c-CRK link c-ABL, p190 $\mathrm{BCR} / \mathrm{ABL}$ and $\mathrm{p} 210^{\mathrm{BCR} / \mathrm{ABL}}$ to the phosphatidylinositol-3' kinase pathway. Oncogene 1996;12:839-46.

48. Zhang Z, Vuori K, Wang H-G, Reed JC, Ruoslahti E. Integrin activation by R-ras. Cell 1996;85:61-9.

49. Gotoh A, Miyazawa K, Ohyashiki K, Tauchi T, Boswell HS, Broxmeyer HE, et al. Tyrosine phosphorylation and activation of focal adhesion kinase ( $\mathrm{p} 125 \mathrm{FAK}$ ) by BCR-ABL oncoprotein. Exp Hematol 1995;23:1153-62.

50. Salgia R, Li JL, Lo SH, et al. Molecular cloning of human paxillin, a focal adhesion protein phosphorylated by P210BCR/ABL. J Biol Chem 1995;270:5039-47.

51. Skorski T, Kanakaraj P, Nieborowska-Skorska M, et al. Phosphatidylinositol-3 kinase activity is regulated by BCR/ABL and is required for the growth of Philadelphia chromosomepositive cells. Blood 1995;86:726-36.

52. McWhirter JR, Wang JY. An actin-binding function contributes to transformation by the bcr/abl oncoprotein in Philadelphia chromosome positive human leukemias. EMBO J 1993;12:1533-46. 